Theories \& Applications, the International Edition

Printed Version : (ISSN 2090-5262)

Online Version : (ISSN 2090-5270)

November 2014, Volume 4, No. 3 Pages (127 - 130)

\title{
The Effects of Coordination Abilities Program on Accuracy and Speed of the Offensive Skills among Youth Table Tennis Players.
}

\author{
Dr. Wael Kandil \\ Assistant professor, Faculty of physical Education -Al Sadaat City University, Egypt. \\ Dr. Tariq Muhammad Ali \\ Faculty of Physical Education, Benha University, Egypt.
}

\begin{abstract}
The aim of this study was to explore the effects of coordination abilities program on accuracy and speed of the offensive skills among youth table tennis players. The sample was comprised of 40 youth table tennis players under age, 12 years. The subjects divided into two groups. The experimental group $(n=20)$ participated in coordination abilities training program. The time is done for three times weekly for eight weeks. The control group $(n=20)$ participated in the traditional program only. The results of this study showed that the experimental group higher scores than the control group in Coordination abilities and offensive skills. These results were revealed that Coordination abilities training are effectively, and the best offensive performance would be expected to be more Coordination abilities.
\end{abstract}

Keywords - Coordination Abilities, Offensive Skills, Table Tennis.

\section{Introduction}

$\mathrm{T}$ able tennis is a fast sport and playing table tennis is a difficult motor task that requires fast movements, accurate control, and adapt to task parameters (Katharina, et a!. 2011). Even for a normal human being to manage accurate umpiring, especially in services (serves), which usually take less than a second to complete. The umpire needs to make over 30 observations and makes a judgment before or soon after the service is complete.(Mufti Ibrahim 1998) Motor performance capabilities are divided into sports physical capabilities, consensual capabilities, capabilities mixed These capabilities are broad-based access to good performance skills ( Ji and Huang 1987) It was also agreed in this direction to Nasrelddin Radwan and Kamal Abdul Hamid (1994), Mohamed Sobhi (1999)and Fikry Hassan (1999), that the diagnosis appears in identifying strengths and weaknesses of the thing to be evaluated and try to identify the causes either therapy is to develop appropriate solutions to overcome the weaknesses and take advantage of the strengths.

Also Mohamed Sobhy confirmed (1999) on the calendar in physical education does not come from the previous concepts, it includes an estimate of the performance or the players then the verdicts on this performance in light of the specific considerations for performance specifications. The coordination abilities of the main pillars of performance skills where are a common denominator and a boat with other elements to contribute to access the player to the highest level athlete according to the potential physical, we find that the novices who are characterized by coordination abilities degree was higher than their peers, which can register a higher degree of physical capacities of public, and that depend on them both of fitness and fitness skills, and does not relate to motor harmonic performance capabilities only, but also the skills vehicle which is characterized by a degree of difficulty and complexity in the tactical aspects and tactics.

This was confirmed by Mohamed Sobhy (1999) that novices who lose a certain amount of coordination abilities caused him great difficulty in access to performance mechanism as well as the lack of balance between the movements and outcomes of the skill level of difficulty of performance. The coordination abilities is the key to the success of education and to improve and develop the level of performance skills, availability of these capabilities to properly and accurately helps good thinking and ease of learning motor skills and development, and the development level of coordination abilities plays an important role when the acquisition of motor skill, and that these skills express foundation composite level skill and working to develop this capacity, and coordination abilities gathered between the expectations and the performance requirements kinetic and psychological longer the boot performance motor while the motor performance is the actual implementation of the movement, as it represents consistency between the central nervous system and muscles during phases of performance skills.

The player acquires harmonic capacity through motor learning and requires the development of a synergy activate both cognitive abilities and sense of mobility for self-control in the performance of movements.

The coordination abilities contribute to the installation of total traffic movement's partial manner consistent if the level of synergy year required completing motor skills, and the development level of performance skills is not obligatory 
for beginners only, but is also the duty of the player's applicants to ensure continuous improvement and development of performance and mastery and install it.

And according to Amrala Bisatti (1996) Mufti lbrahim (1998), Ibrahim Shaalan and Amr Abu Glory (1996) that the planning for the training of junior activities various sports aims to acquire motor skills essential in general as well as the development of the physical attributes to get them to achieve the highest levels of the sport practice and preserve it for as long as possible so that each player implementation plans entrusted to him by the duties of the center, which holds in the lines different play during the match to the fullest, and must occupy harmonic capacity exercises a large part of the training program for beginners.

Since at this stage if there are no adequate interoperability capabilities of novices cause him great difficulty in access to performance mechanism as well as the lack of balance between the movements and outcomes of the skill level of difficulty of the performance.

The coordination abilities enables one to have the conscious and accurate perception of the strength, timing and spatial parameters of a range of movement, which leads to various motor skills being more efficient and fluid (Raczek, et a.2002;Starosta,2003). The essence of coordination abilities is its capability in positioning the body's joints (the spatial component), activating the strength of the involved muscles (the strength component) and the speed of the involved movement (the temporal. component) (Starosta,2003. 1983).Coordination abilities have been identified as one of the most important factors of motor coordination (Starosta,2003;Bajdzinski, et al. 2002). Previous literature has emphasized its importance in sport, but also stressed its complex and variable character which depends on a number of factors, including the difficulty in selecting which methods can be used to assess such an. ability (Starosta, 1983 ;Zaton, et al. 2009). Many studies have made reference to the fact that coordination abilities should be based on the performance level found in national sport competition and, as such, be considered in the selection process of sport disciplines. Previous studies have also reported on coordination abilities and its relationship with the level of play depending on which sport disciplines were considered. (Starosta, 2006) conducted a study on figure skaters and found interdependence between their kinesthetic sensibility and their skill level, and also showed that a higher skill level in sport is associated with greater movement accuracy (in performing specific moves).

In addition, Zajac et al.(1992) in a study of basket ballplayers, found that an increasing level of competitions accompanied by a higher level of upper limb strength, confirmed by similar observations made by Ji \& Huang (1987). Starosta et al. (2003)Found a significant increase in the differentiation movement levels between the ready phase and start phase of kayakers, Therefore, the authors state that to explore the effects of coordination abilities program on accuracy and speed of the offensive skills among youth table tennis players.

\section{Material and Methods}

\section{Experimental Approach to the Problem}

Two groups (experimental and control), performed a pre and post training designed intervention in which coordination abilities and offensive skills were recorded. The experimental group trained one hour per day 3 times a week on coordination abilities training besides the table tennis training for eight weeks.

The control group continued their normal training, while the experimental group completed coordination abilities training program to see whether this type of training modality would have a positive or negative or no effect on coordination abilities and offensive skills.

\section{Participants}

The sample was comprised of 40 youth table tennis players under age. 12 years. The subjects divided into two groups. The experimental group $(n=20)$ participated in coordination abilities training program. Three times weekly to eight weeks. The control group $(n=20)$ participated in the traditional program only one table shows the basic characteristics of the sample

Table (1):

The basic characteristics of the sample

\begin{tabular}{|c|c|c|c|c|c|c|}
\hline Variables & Measurement unit & Mean & $\begin{array}{c}\text { Standard } \\
\text { deviation }\end{array}$ & Median & Splaying & Seqwence \\
\hline Age & Year & 10.69 & 0.382 & 10.77 & -0.637 & -0.656 \\
\hline Height & $\mathrm{Cm}$ & 145.17 & 2.78 & 145.00 & -0.751 & -0.122 \\
\hline weight & $\mathrm{kg}$ & 43.00 & 2.07 & 43.00 & -0.627 & 0.125 \\
\hline
\end{tabular}

Table (I) shows the coefficient of torsion of the growth variance of a sample of basic research is limited between 3, which refers to the homogeneity of the research sample.

\section{Procedures:}

There searchers select variables according to the references and previous studies, and the basic skills which will be included in the proposed training program are:

\section{Firstly, coordination abilities:}

- The ability to accurately determine the status (DS)

- The ability to control of the motor rhythm(MR)

- $\quad$ The ability to control of the motor balance(MB)

- The ability of the motor organizes(MO)

- $\quad$ The ability to the reaction speed (RS)

Secondly: offensive table tennis skills: 
- Counter forehand (CF).

- $\quad$ Counter backhand (CB)

- $\quad$ Forehand top spin (PS).

- $\quad$ Backhand top spin (BS)

Results:

Table (2):

Coordination abilities and offensive skills Scores for two groups

\begin{tabular}{|c|c|c|c|c|c|c|c|}
\hline \multirow{2}{*}{ variables } & \multicolumn{3}{|c|}{ control } & \multicolumn{3}{|c|}{ experimental } & \multirow{2}{*}{$\begin{array}{l}\text { T.sign } \\
\text { between } \\
\text { groups }\end{array}$} \\
\hline & pre & post & $\mathrm{T}$ sign & pre & post & $\mathrm{T}$ sign & \\
\hline (DS) & 11.251 .61 & 8.401 .47 & Sign & 11.201 .64 & 8.401 .47 & Sign & Sign \\
\hline (MR) & 8.750 .91 & 5.700 .86 & Sign & 8.600 .99 & 5.700 .86 & Sign & Sign \\
\hline (MB) & 12.951 .64 & 16.301 .30 & Sign & 12.901 .65 & 16.301 .30 & Sign & Sign \\
\hline (MO) & 4.300 .66 & 6.050 .83 & Sign & 4.150 .81 & 6.050 .83 & Sign & Sign \\
\hline (RS) & 193.502 .26 & 168.756 .53 & Sign & 193.751 .86 & 168.756 .53 & Sign & Sign \\
\hline (CF) & 12.701 .22 & 14.251 .25 & Sign & 12.551 .32 & 17.101 .33 & Sign & Sign \\
\hline (CB) & 13.001 .34 & 14.451 .32 & Sign & 12.851 .35 & 17.251 .41 & Sign & Sign \\
\hline (FS) & 11.301 .22 & 12.651 .31 & Sign & 11.201 .97 & 14.300 .92 & Sign & Sign \\
\hline (BS) & 9.801 .32 & 10.801 .47 & Sign & 9.701 .34 & 13.251 .12 & Sign & Sign \\
\hline
\end{tabular}

Data in Table (2) shows that there is a significant difference in overall coordination abilities and offensive skills, between the pre- and post-training.

Significant differences between the two groups in overall coordination abilities and offensive skills, coordination Abilities are responsible for the difference observed.

\section{Discussion}

The results of this study showed that the experimental group higher scores than the control group in Coordination abilities and offensive skills. These results were revealed that Coordination abilities training effectively. And the best offensive performance would be expected to be more Coordination abilities.

Its fundamental nature is the perception of movement while it is happening, allowing such a movement to be better controlled. Literatures that studied and assessed the level of differentiation ability and its determinants and relationships often find that the level of this ability determines, to a large extent, success in many sport disciplines. Such a dependency was found by Starosta in figure skaters, by Starosta et al. (1989) in kayakers, by Zajacet aI. (1992) In basketball players and by Stefaniak,(2008) in martial art athletes. The highest level of kinesthetic sensitivity found in these athletes especially applies to the particular body limbs more involved in that sport's physical movement: the lower limbs for figure skaters, the upper limbs for boxers or the lower limbs for karate practitioners (Starosta,2003, 1989).

Ji and Huang (1987) also observed a high level of kinesthetic sensitivity in the hands and elbows of basket ballplayers, which was similar to what Zajac et al.(1992) observed. Some researchers also claimed to find relationship between kinesthetic differentiation and high-level training techniques. Such dependencies were found by Cynarski et
aI. (2005) in karate practitioners, by Buraczewski et al.(2008) in football players and byStarosta et aI. (1989) in kayakers. Also, many correlations have been found between kinesthetic differentiation ability and the level of sport played or advanced sports techniques used in game play; thanks to a high kinesthetic sensitivity one can more accurately control their movement.

(Raczek . et al. 2002; Bajdzinski, et aI. 2002 In addition, through kinesthetic impression, the "focus" (Starosta,2003.1983.

1978;2006) on one's bodily movement is far fuller and richer, where the functioning of one's telereceptors is supplemented by proprioceptor stimuli (Raczek, et al. 2002). Thanks to this "extra" information, loaming new 1110ior skills is more precise. However, as has been found in relevant research, the importance of visual and kinesthetic infonnationis still disagreed upon (FarahaL et al. 2004; Fery $\&$ Morizot 2000). This study assumed that the spon of table tennis requires a high level of kinesthetic differentiation ability(Hotz \&MusterI993;Bankosz, 2008;Bankosz \& Skarul 2010). This ability is manifested in table tennis due to the numerous skills needed to be effective in

This game, above all the ability to sense and adapt to game dynamics (the speed of the game, the spinning of the ball correctly landing the ball on the table, etc.) (Hotz \&Muster 1993).Adjusting the angle of one's paddle when hitting a ball (something which occurs in a split second) most probably is also a derivative of kinesthetic differentiation ability.

\section{Conclusion}

The findings of this study indicated that Coordination abilities are related to performance success. Coaches working with athletes need to take these factors into their account when preparing for competition. 


\section{References}

1. Amrala Bisatti. Physical training and preparation in football, facility knowledge, Alexandria, 1996.

2. Bajdzinski M., Starosta W., kinesthetic differentiation of movement and its implicati9ns (in Polish). Miydzynarodowe Stowarzyszeqie Motoryki Sportowej, Warszawa-Gorzow Wielkopolski 2002, 30-46.

3. Bailkosz Z., Accuracy of movement repeatability and sport level of table tennis players. In: Sadowski J., NimikowskiT. (eds.), Coordination motor abilities in scientificresearch. A WF, WarszawaBiala Podlaska 2008,46-52.

4. Bailkosz Z., Skarul A., Changes in the level of kinestheticdifferemiarion ability in table tennis players. Studies inPhysical Culture \& Tourism, 2010,17 (1), 4]--46.

5. Buraczewski T., Cicirko L., Storto M., Correlation between the level of development of coordination motor abilities and a special skill in children at the beginner's stage of football training. In: Sadowski J., Ninikowski T. (eds.), Coordination motor abilities in scientific research. A WF, Warszawa-Biaa Podlaska 2008,66-71.

6. Cynarski W.J., Obodyilski K., Litwiniuk A., The technical advancement and level of chosen coordination abilitiesof people practicing karate. In: Sadowski J. (ed.),Coordination motor abilities in scientific research. A WF,Warszawa-Biala Podlaska 2005, 428--433.

7. Farahat E., me A., Thon B., Effect of visual and kinestheticimagcry 011 The leaming of a pattemed movement.lnt J Sport Psychol, 2004, 35 (2), ] 19 132.

8. Fery Y.A., Morizot P., Kinesthetic and visual image inmodeling closed motor skills: the example of the tennisserve. Percept Mot Skills, 2000,90 (3), 707 722.

9. Fikry Hassan. Teaching - its objectives - founded tactics - Evaluating the results - applications, the world of books, i 4, Cairo, 1999.

10. Hotz A., Muster M., Table tennis: teaching and leaming(in German). Meyer \& Meyer, Aachen 1993, 14-23.

11. Ibrahim Shaalan and Amr Abu Glory Defense strategy in football, the Arab Thought House, Cairo, 1996.

12. Ji L., Huang B., A discussion on psychological characteristicsof female basketball sharpshooters. Sport Sci,1987, 7 (2), 61-64.

13. Katharina Millling,Jens Kober,Jan Peters. A biomimetic approach to robot table tennis. Adaptive
Behavior October 201lvol. 19 no. 5 359-376

14. Mohamed Sobhy . Evaluation and measurement in physical education, the first part, the Arab Thought House, Cairo, 1999.

15. Mufti Ibrahim . Building and team development in contemporary football, Arab Thought House, Cairo, 1999.

16. Nasreddin Radwan and Kamal Abdul Hamid Introduction to Physical Education Calendar, Dar Alvkraraby, Cairo in 1994.

17. Raczek J., Ljach W., Mynarski W., Development andevaluation of coordination motor abilities (in Polish).A WF, Katowice 2002.

18. Starosta W., Aniol-Strzyzewska K., Fostiak D., JablonowskaE., Krzesinski S., Pawlowa-Starosta T., Precision oflsinesthetic sensation - element of diagnosis of performanceof advanced competitors. BioI Sport, 1989, 6 (Suppl. 3), 265-271.

19. Starosta W., Co-ordination motor abilities (in Polish).Mi arodowe Stowarzyszenie Motoryki Sportowej,Warszawa 2003.

20. Starosta W., Precision of movement - one of factors oftechnica1 preparation (in Polish). Zeszyty Naukowe A WFwe Wroclawiu, 1983, 33,63-79.

21. Starosta W., The accuracy of kinesthetic sensations andthe sport level (in Polish). Monografie A WF w Poznaniu, 1978, 115,513-523.

22. Starosta W., The concept of modem training in sport. Studies in Physical Culture \& Tourism, 2006, 13 (2), 9-23.

23. Stefaniak T., Precision in recreation of the set power by combat sports athletes (in Polish). Studio i MonografieA WF we Wroclawiu, 2008, 90,62-72.

24. Zaj!!c A., Kubaszczyk A., Raczek J., Tiredness and the level of kinesthetic differentiation of upper limbs among basketball players (in Polish). Rocznik Naukowy A WFw Katowicach, 1992. 20. 63-70.

25. Zaton M., Blacha R, Jastrz;rbska A.. Slonina K., Repeatability pressure force during elbow tlexion and extension before and after exercise. Hum Mov, 2009, 10 (2),137-143, doi: 1 0.2478/v1 0038-009$0010-($ 
